\title{
Analysis of Surrounding Rock Creep Effect on the Long-Term Stability of Tunnel Secondary Lining
}

\author{
Xiaoqian Zhang $\mathbb{D}^{1},{ }^{1}$ Chengmin Wei $\mathbb{D}^{2},{ }^{2}$ and Heng Zhang $\mathbb{D}^{2}$ \\ ${ }^{1}$ School of Architecture \& Civil Engineering, Liaocheng University, Liaocheng, Shandong 252059, China \\ ${ }^{2}$ College of Emergency Management and Safety Engineering, China University of Mining and Technology (Beijing), \\ Beijing 100083, China \\ Correspondence should be addressed to Chengmin Wei; kdaqwcm@163.com
}

Received 17 July 2021; Accepted 2 August 2021; Published 9 August 2021

Academic Editor: Gan Feng

Copyright (c) 2021 Xiaoqian Zhang et al. This is an open access article distributed under the Creative Commons Attribution License, which permits unrestricted use, distribution, and reproduction in any medium, provided the original work is properly cited.

\begin{abstract}
The secondary lining failure of deep buried soft rock tunnel often occurs, which is obviously related to the time factor. The formation mechanism of this phenomenon is studied in this paper. Therefore, the combination of in situ stress measurement and neural network inversion is used to analyze the distribution characteristics of in situ stress. At the same time, the creep characteristics of surrounding rock are tested in laboratory, and the key parameters are obtained. Combined with the characteristics of surrounding rock, the calculation model is established by using discrete element simulation technology and considering the joints of surrounding rock. According to the above multiple information, the stress characteristics of the secondary lining in different time periods are analyzed creatively. Finally, the method of setting arch and adding anchor bolt in key parts is proposed, and significant effect results are obtained.
\end{abstract}

\section{Instruction}

At present, tunnel construction is gradually moving towards complex geological regions with relatively little engineering experience, and the rock formations in many of its areas are showing significant creep characteristics and causing numerous problems of tunnel second lining instability. $\mathrm{Nu}-$ merous experts have made many studies on this problem. Xu et al. [1] discussed the tunnel in phyllite weak and broken stratum as an example, and the cracking of secondary lining was investigated. Then, the failure process of the secondary lining is studied by using the similar model test and the particle discrete element method. Liu et al. [2] analyzed the intrinsic model of the coupling action of anchor rod/anchor cable and creeping surrounding rock, studied the variation law of anchor rod/anchor cable on the anchoring force of surrounding rock with time, analyzed the physical and mechanical parameters of anchor rod/anchor cable and the mechanical parameters of surrounding rock, and compared the sensitivity of the above parameters on the anchoring force by using the sensitivity analysis method. The triaxial unloading creep tests of prefractured coal samples were carried out under constant axial pressure and graded unloading confining pressure, and the axial and lateral creep laws of fractured coal samples with different dip angles were studied [3]. Qi and Fourie [4] proposed a modeling framework considering the time-varying properties of creep solids, such as stiffness and cohesion over time. The effect of filling on the stress distribution of stope is studied. Fang et al. [5] collected undisturbed soil samples from tertiary mudstone, studied the creep process and failure mechanism of surrounding rock through indoor model test of underground tunnel, proposed influence of time and stress on creep parameters and mechanical parameters, introduced the concepts of over stress difference and time product, and established a damage model considering time and stress state [6-8]. A model describing the whole process of rock creep is introduced, which can correspond to each stage of rock creep. A new method for determining creep parameters is proposed. The relationship between creep parameters, stress difference, and time product is analyzed. A creep model considering the effects of stress and time is established 
[9-12]. Triaxial unloading creep tests of soft soil under different initial excess pore water pressures $(0,20,40$, $60 \mathrm{kPa}$ ) were carried out. The results show that the unloading creep of soft soil can be divided into three stages: attenuation creep, constant speed creep, and accelerated creep [13]. Liu et al. [14] adopt the method of combining theoretical analysis and numerical simulation, adopt the nonlinear creep model, and use FLAC3D software for secondary development to study the creep characteristics of rock salt. Huang et al. [15] used rock triaxial rheometer and acoustic emission system to carry out creep test under high stress level. Based on the short memory effect of creep stage, a creep model was established and its validity was verified. Using the creep model, they analyzed the deformation problem and control strategy in engineering [16-19].

Firstly, through geological investigation and analysis, this paper studies the regional geological characteristics and studies the in situ stress field according to the measured data of in situ stress and neural network. At the same time, the cracking and stress characteristics of secondary lining concrete are analyzed. Finally, a solution based on "steel frame arch + anchor" is proposed.

\section{Engineering Geological Analysis}

2.1. Geological Overview. Erlangshan high-speed tunnel site area is located in the northeast side of the "Y" tectonic intersection of the northwest trending Xianshui River tectonic zone, northeast trending Longmen Mountain tectonic zone, and north-south trending Sichuan-Yunnan tectonic zone, mainly through the Longmen Mountain tectonic zone, and the geological structure is extremely complex. The tunnel body crosses seven fracture zones at a large angle, as shown in Figure 1. The main strata exposed in the tunnel site area are Aurignacian magmatic rocks, Triassic, Devonian, Silurian, Ordovician sedimentary rocks, and Quaternary accumulation layers.

\subsection{In Situ Stress Measurement and Inversion of Tunnel.} Stress distribution characteristics and stress levels in the tunnel play a crucial role in the stability of the surrounding rock. After tunnel excavation, the stress state of the original surrounding rock will change, and the stress will be redistributed, and stress concentration will also occur. This stress concentration can easily lead to large deformation of soft rock, rock burst, and creep. It is important to analyze the stress characteristics of the target area. The ground stress in the tunnel was measured by the hydraulic fracturing method, and the results are shown in Figure 2.

According to the analysis of in situ stress, the maximum horizontal principal stress is about $13 \sim 16 \mathrm{MPa}$ when the tunnel depth is $300 \sim 340 \mathrm{~m}$. When the buried depth is between 520 and $570 \mathrm{~m}$, the maximum horizontal principal stress is about $14 \sim 15 \mathrm{MPa}$. The horizontal principal stress increases with the depth. The vertical principal stress can be estimated by the weight of the overlying rock mass.

The initial stress field of the rock mass is related to the self-weight stress, shear tectonic stress, and horizontal tectonic stress of the rock mass. Therefore, in order to conduct a

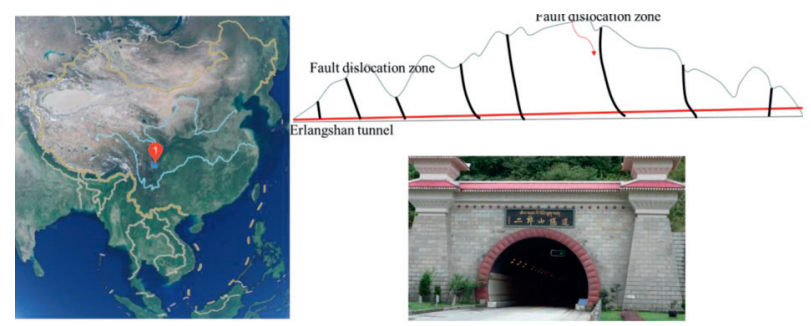

FIGURE 1: Tunnel location and geological section.

comprehensive ground stress characterization, the regional ground stress field is analyzed by numerical combined with the neural network inversion method. The following three boundary conditions are considered: the first boundary condition is based on the vertical stress, considering the influence of the pressure measurement coefficient on the initial ground stress of the rock mass; the second boundary condition is to consider the tectonic motion in the $x$ and $y$ directions and to apply a unit uniform load of equal magnitude in the two faces perpendicular to the axial direction; the third boundary condition is to consider the tangential tectonic motion in the plane and to apply a load of equal magnitude along the $z$-axis with a negative The third boundary condition, considering the tangential tectonic motion in the plane, applies a tangential uniform load of equal magnitude along the negative direction of $z$-axis.

The inversion method of IA-BP (Immune Algorithm + BP) neural network is adopted, combining with the measured and simulated data of in situ stress, and the inversion process is shown in Figure 3. The weights and thresholds of BP neural network are optimized by immune algorithm, and the in situ stress inversion method of IA-BP algorithm is established. The back analysis program is written by using MATLAB language toolbox [20-22]. The steps are as follows: use $3 \mathrm{DEC}$ software to calculate the above boundary conditions and construct learning samples. The structure parameters of BP neural network are initialized, and the number of nodes in the input layer, output layer, and the number of neurons in the hidden layer are set. Set the number of immune genes and population, and the number of genes $D$ is the sum of all weights in BP network. If the number of neurons in each of the three layers of BP neural network is $S 1, R$, and $S 2$, respectively, the dimension of particle swarm optimization can be expressed by

$$
D=S_{1} \times R+S_{2} \times R+S_{1}+S_{2} .
$$

The affinity function is shown as

$$
\text { aff }=\frac{1}{1+\sum_{k=1}^{m} \sum_{t=1}^{q}\left(y_{t}^{k}-c_{t}^{k}\right)^{2}}
$$

where $m$ is the number of samples, $q$ is the number of output neurons, and $y_{t}^{k}$ is the expected output value of the th output neuron of the $k$ th sample. $c_{t}^{k}$ is the actual output value of the th network output neuron of the $k$ th sample.

According to the above formula, we can get the affinity and add the antibody with high affinity to the antigen into the memory cell. By calculating the expected value of the antibody, 


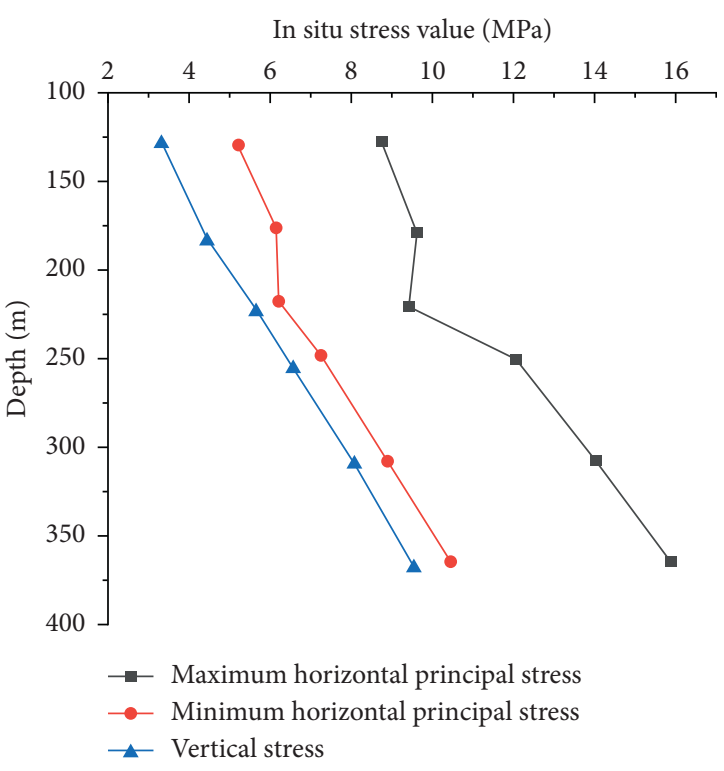

(a)

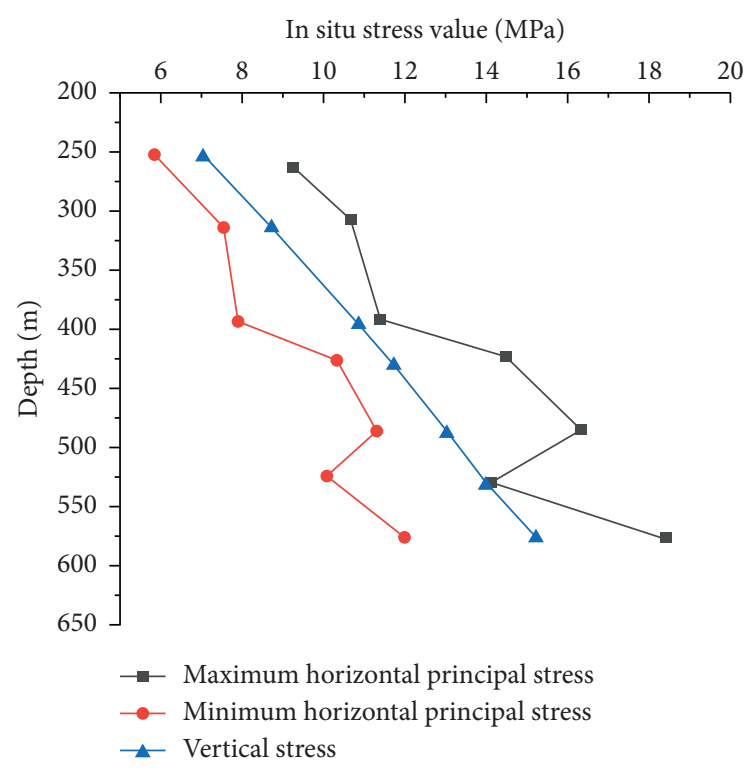

(b)

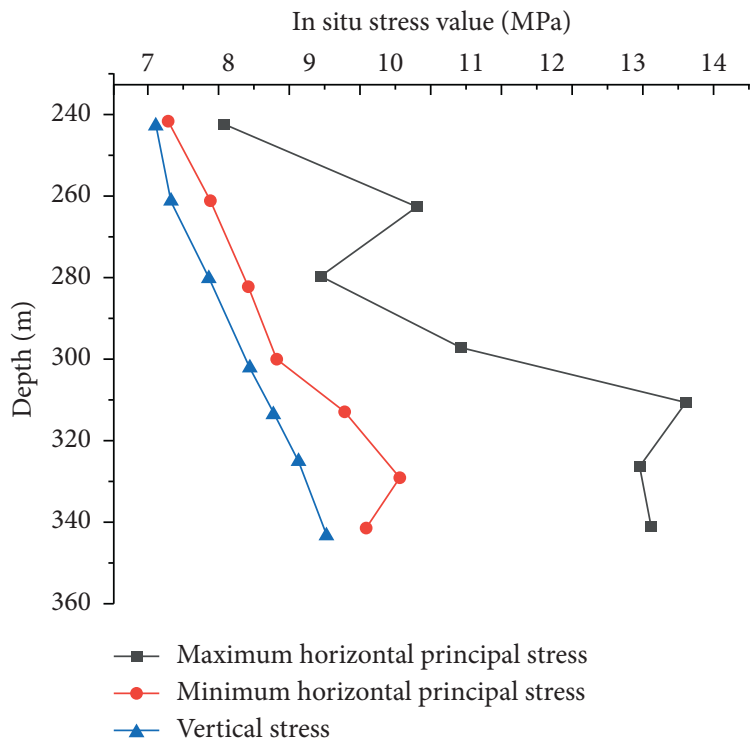

(c)

Figure 2: Initial stress change rule of test value with depth. (a) In situ stress test $1 \#$. (b) In situ stress test 2\#. (c) In situ stress test $3 \#$.

we can eliminate those antibodies with low expected value. If it meets the requirements, determine the fitness value of the optimal individual and take it as the weight and threshold of the neural network. If not, repeat the above steps 4 and 5 .

The immune algorithm is used to learn the numerical results, adjust the corresponding structural parameters, then use the measured stress data to test, and establish the nonlinear corresponding relationship between the numerical results and the measured results. The final in situ stress inversion results are shown in Figure 4.

\subsection{Mechanical Tests on Creep Characteristics of Mudstone.} The mudstone samples were processed into cylinders of $50 \mathrm{~mm}$ in diameter and $100 \mathrm{~mm}$ in height for creep test studies. The surrounding pressure was set at $25 \mathrm{MPa}$, and triaxial creep tests with multiple specimens and singlestage loading were carried out. The difference between the axial stress and the surrounding pressure was recorded as the partial stress. The loading rate of axial stress was $0.365 \mathrm{MPa} / \mathrm{min}$. The applied partial stresses were $15 \mathrm{MPa}$, $20 \mathrm{MPa}, 25 \mathrm{MPa}, 30 \mathrm{MPa}, 33 \mathrm{MPa}$, and $36 \mathrm{MPa}$. The test results are shown in Figure 5. The test results show that the creep stress threshold of the mudstone is low, and the stress and time have a large influence on the creep characteristics of the mudstone. As the stress level increases, the instantaneous elastic strain generated at the moment of bias stress application increases and exhibits three intuitive phase characteristics, namely, decay, steady state, and acceleration. 


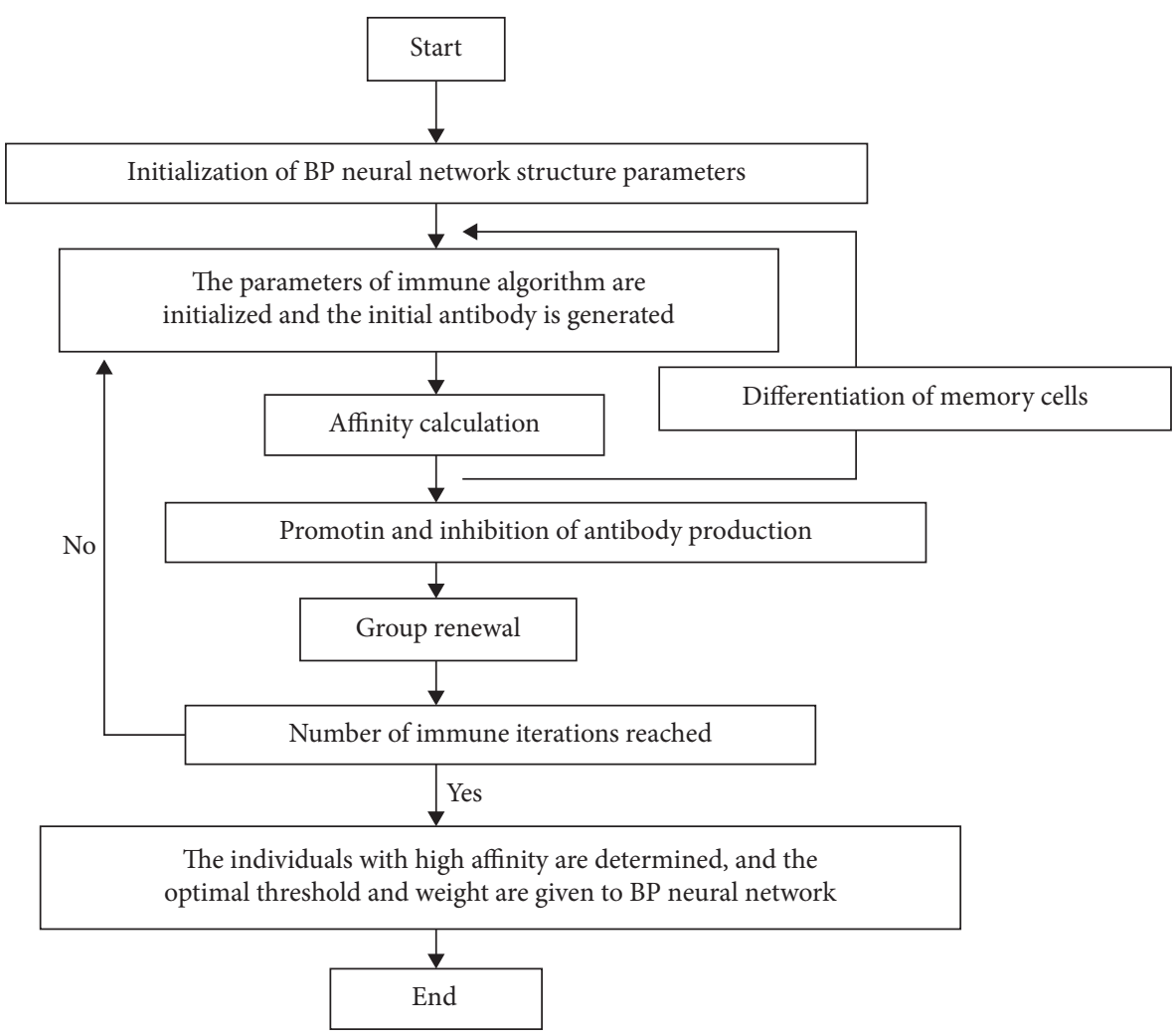

FIgURE 3: Stress inversion flowchart.

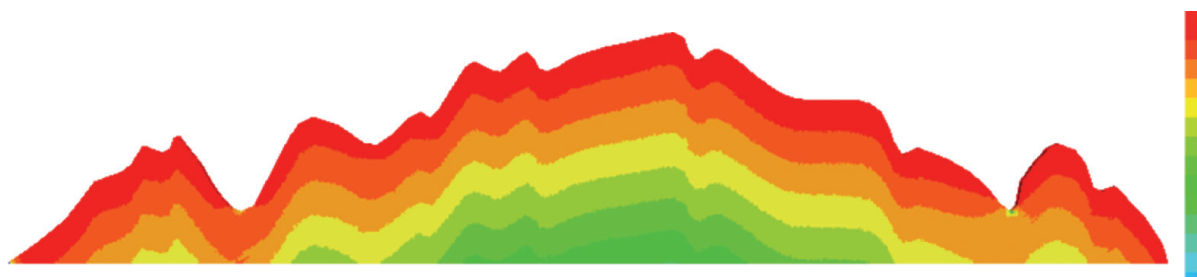

$3.0459 E+05$

$-2.5000 E+06$

$-5.0000 E+06$

$-5.0000 E+06$
$-7.5000 E+06$

$-1.0000 E+07$

$-1.2500 E+07$
$-1.500 E+07$
$-1.7500 E+07$

$-1.7500 E+07$

$-2.0000 E+07$
$-2.2500 E+07$
$-2.500 E+07$

$-2.2500 E+07$
$-2.500 E+07$
$-3.7500 E+07$

$-2.7500 E+07$
$-3.0000 E+07$

FIgURE 4: Stress inversion results.

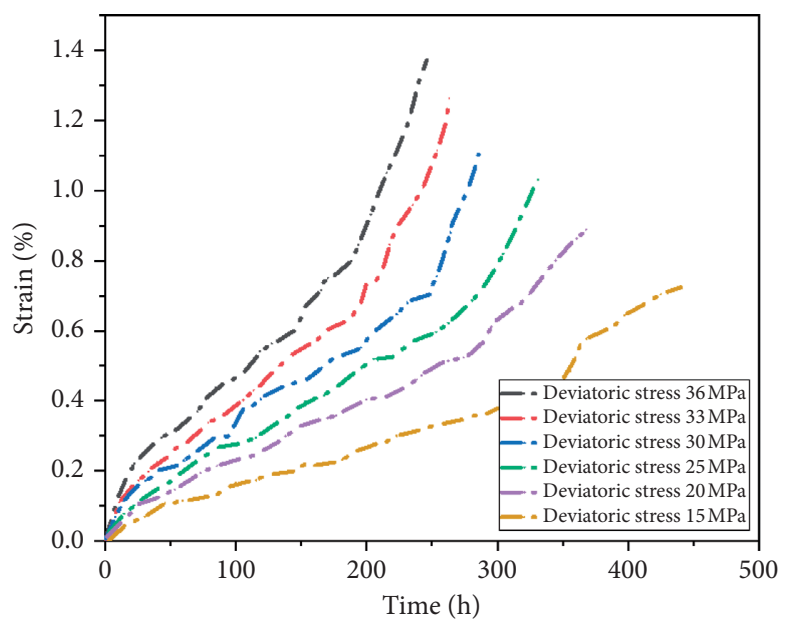

Figure 5: Creep test results of mudstone under different stress. 


\section{Tunnel Lining Damage Characteristics and Its Numerical Modeling}

3.1. Damage Characteristics. Take section $\mathrm{K} 2737+$ $715 \sim \mathrm{k} 2737+753$ as an example, and the cracks at the left and right arch waist that have penetrated the lining and deformation are serious, as shown in Figure 6, and the lining strength and thickness meet the requirements. During the construction period, the section collapsed more than ten times continuously with the maximum collapse depth of $10 \mathrm{~m}$.

3.2. Numerical Modeling. The tunnel is simulated by $3 \mathrm{DEC}$ discrete element software. The model type is the 3D model. The simulation area is $31 \mathrm{~m}$ in $X$ direction, $30 \mathrm{~m}$ in $Y$ direction, and $30 \mathrm{~m}$ in $Z$ (vertical) direction with the tunnel contour as the center, as shown in Figure 7. The upper and lower boundaries of the tunnel are fixed with $Y$-direction displacement degrees of freedom, and the left and right boundaries are fixed with $X$ direction displacement degrees of freedom. In the target area, the buried depth of the tunnel is $240 \mathrm{~m}$. The maximum horizontal stress is $11 \mathrm{MPa}$ ( $x$ direction), the minimum horizontal stress is $7 \mathrm{MPa}$ ( $x$ direction), and the vertical stress is $6 \mathrm{MPa}$.

The model includes surrounding rock, excavation part, and tunnel secondary lining. The surrounding rock joints are divided by the DFN model, and the joint data are from the field geological survey.

3.3. Constitutive Model and Calculation Parameters. Creep of jointed rock mass comes from two parts: one is creep of rock and the other is creep of joint plane. The stress-strain relationship of rock under creep condition is as follows [23-26]:

$$
\varepsilon_{i j}=J_{1}(t) \sigma_{i j}+\frac{J_{2}-J_{1}(t)}{3} \sigma_{k k} \delta_{i j}
$$

If the normal and tangential creep deformation laws of the joint surface are consistent with the generalized Kelvin model, then there are [27-29]

$$
\begin{aligned}
& \frac{1}{K_{n n}(t)}=\frac{1}{G_{1 n}}+\frac{1}{G_{2 n}}\left[1-\exp \left(\frac{-G_{2 n} t}{\eta_{n}}\right)\right], \\
& \frac{1}{K_{s s}(t)}=\frac{1}{G_{1 s}}+\frac{1}{G_{2 s}}\left[1-\exp \left(\frac{-G_{2 s} t}{\eta_{s}}\right)\right] .
\end{aligned}
$$

The creep flexibility tensor of the joint surface is as follows:

$$
C_{i j k l}^{J}(t)=\sum_{r=1}^{M} n_{i}^{r} T_{j p}^{r} D_{p q}^{r}(t) T_{l q}^{r} n_{k}^{r} \frac{1}{d^{r}}
$$

The creep relation of jointed rock mass can be expressed as follows:

$$
\begin{aligned}
& \varepsilon_{i j}(t)=C_{i j k l}(t) \sigma_{k l}=\varepsilon_{i j}^{R}(t)+\varepsilon_{i j}^{J}(t), \\
& \varepsilon_{i j}^{R}(t)=C_{i j k l}^{R}(t) \sigma_{k l} ; \varepsilon_{i j}^{J}(t)=C_{i j k l}^{J}(t) \sigma_{k l} .
\end{aligned}
$$

In the formula, $G_{1 n}, G_{2 n}$, and $\eta_{n}$ are the normal elastic modulus, viscoelastic modulus, and viscous coefficient of the joint surface, respectively; $G_{1 s}, G_{2 s}$, and $\eta_{s}$ are the tangential elastic modulus, viscoelastic modulus, and viscous coefficient of joint surface, respectively. The creep flexibility tensor of $C_{i j k l}^{J}(t)$ is a joint surface.

The density, elastic modulus, Poisson's ratio, cohesion, and friction angle of mudstone are obtained from the mechanical property test of surrounding rock, and the creep parameters are obtained from the uniaxial creep test data through data fitting. The values are shown in Table 1.

\section{Numerical Calculation Results and Reinforcement Scheme}

4.1. Analysis of Numerical Calculation Results. In order to conduct a systematic analysis of the forces on the second liner during creep, according to the stress nephogram shown in Figure 8, the maximum principal stress of the second lining unit of the tunnel is negative, which indicates that the second lining of the tunnel is under pressure. The maximum compressive stress before creep is $15 \mathrm{MPa}$ at the foot of the arch, and after creep, the maximum compressive stress at each part of the primary support increases further, and the maximum compressive stress at the foot of the arch reaches $27 \mathrm{MPa}$, which has a greater risk of damage. At the same time, there is also a large stress concentration in the arch waist area, and the maximum stress in the arch waist before creep is $15 \mathrm{MPa}$, and the maximum compressive stress in the arch waist after creep reaches $25 \mathrm{MPa}$.

In order to analyze the support displacement, the horizontal convergence, vault settlement, and arch uplift of the tunnel second liner are extracted and analyzed separately, as shown in Figure 9. Before the creep of the second lining, the horizontal convergence was $0.018 \mathrm{~m}$, the settlement of the vault was $0.007 \mathrm{~m}$, and the elevation of the back arch was $0.0075 \mathrm{~m}$; after 1 year of creep, the horizontal convergence increased by $0.003 \mathrm{~m}$, the settlement of the vault increased by $0.002 \mathrm{~m}$, and the elevation of the back arch increased by $0.0025 \mathrm{~m}$. After 3 years of creep, compared with that before creep, the horizontal convergence increased by $0.004 \mathrm{~m}$, the settlement of the vault increased by $0.0015 \mathrm{~m}$, and the value of elevation arch augmentation increased by $0.0015 \mathrm{~m}$.

4.2. Reinforcement Strategy. According to the analysis of Erlangshan Tunnel lining cracking disease, the deformation of tunnel lining has reached a stable stage. Through the numerical calculation, the key position of the dangerous point is found out, and the "steel frame arch + anchor" is adopted to reinforce the cracked section. At present, the implementation scheme is shown in Figure 10.

After the arch was erected, anchor reinforcement was applied. The anchors were applied mainly in the dangerous areas of the arch waist and arch foot, with the same spacing as that of the steel arch. Finally, C30 concrete was sprayed with a thickness of $18 \mathrm{~cm}$. After adopting this reinforcement strategy, the stability of the tunnel second lining was significantly improved and no cracks or concrete spalling occurred again. 


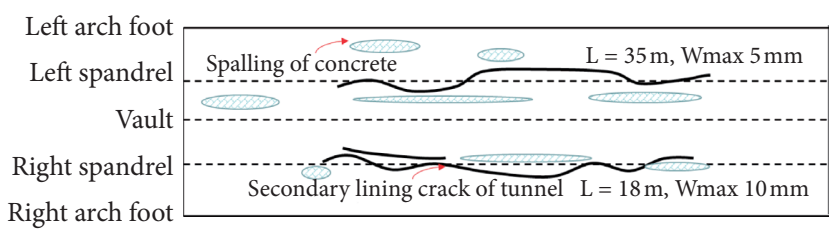

Figure 6: Location of cracks and concrete spalling in tunnel secondary lining.

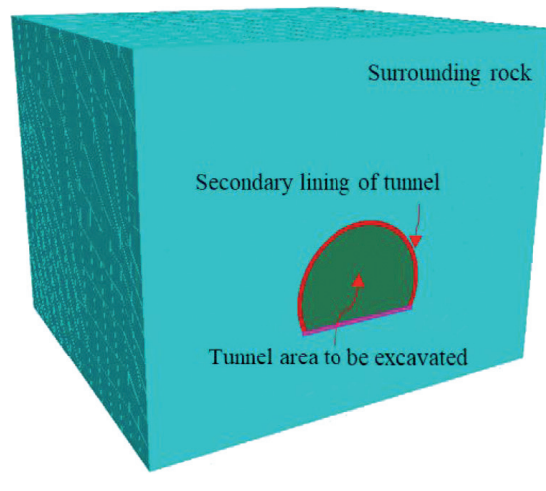

(a)

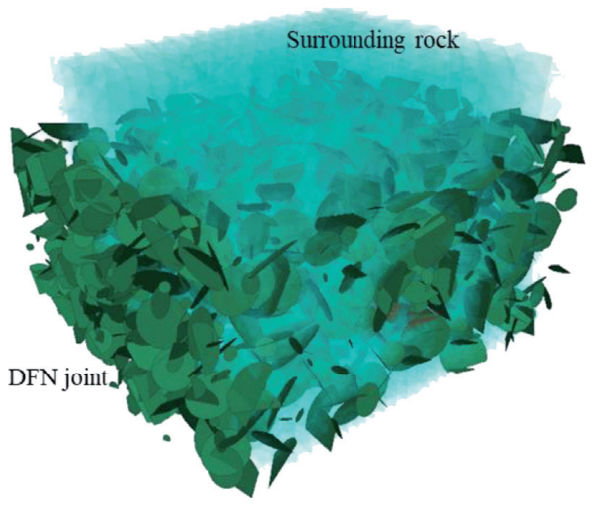

(b)

Figure 7: Numerical modeling. (a) Numerical calculation model. (b) Joint distribution model.

TABLE 1: Rock mechanics parameters.

\begin{tabular}{|c|c|c|c|c|c|c|c|c|c|}
\hline & \multirow{2}{*}{ Density } & \multirow{2}{*}{ Elastic modulus } & \multirow{2}{*}{ Poisson's ratio } & \multirow{2}{*}{ Cohesion } & \multirow{2}{*}{ Friction angle } & \multirow{2}{*}{ Expansion angle } & \multicolumn{3}{|c|}{ Creep parameters } \\
\hline & & & & & & & $A$ & $n$ & $m$ \\
\hline Mudstone & $2500 \mathrm{~kg} / \mathrm{m}^{3}$ & $4087 \mathrm{MPa}$ & 0.37 & 4.86 & 28.22 & 28.12 & $3.127 e^{-22}$ & 2.7345 & -0.698 \\
\hline Second lining & $2900 \mathrm{~kg} / \mathrm{m}^{3}$ & $33,000 \mathrm{MPa}$ & 0.21 & & & & & & \\
\hline
\end{tabular}

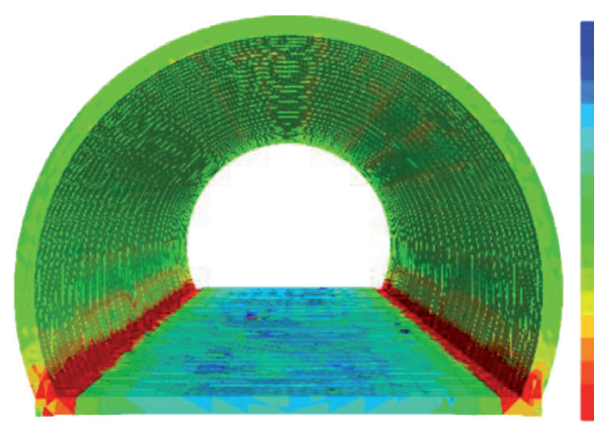

(a)

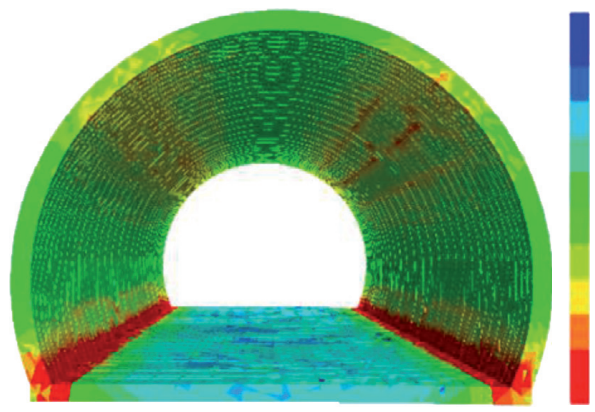

(c)

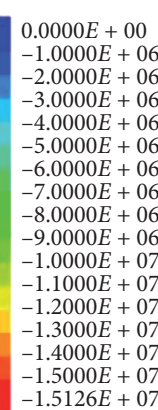

$0.0000 E+00$

$-2.5000 E+06$

$-5.0000 E+06$

$-7.5000 E+06$

$-1.0000 E+07$

$-1.2500 E+07$

$-1.5000 E+07$

$-1.7500 E+07$

$-2.0000 E+07$

$-2.2500 E+07$

$-2.5000 E+07$

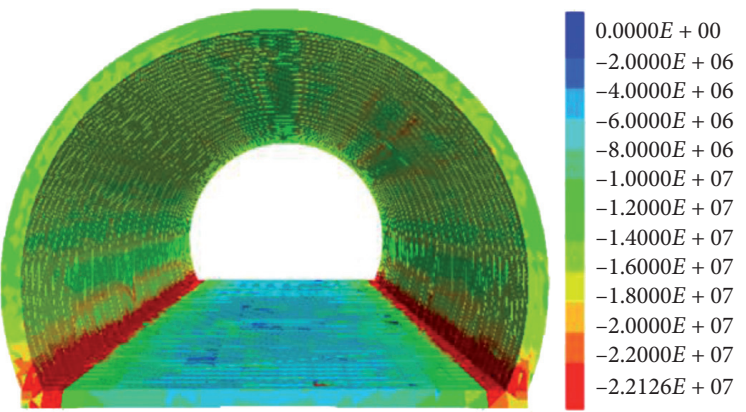

(b)

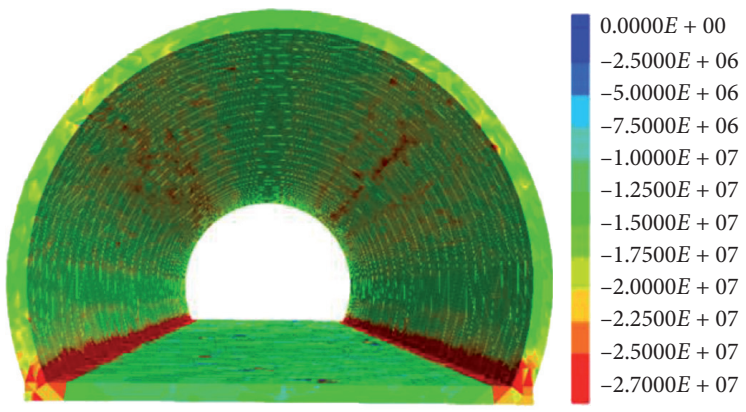

(d)

FiguRE 8: Stress characteristics of tunnel secondary lining under different time conditions. (a) Maximum stress of tunnel before creep. (b) Maximum stress state after creep 0.5 years. (c) Maximum stress state after creep 1 years. (d) Maximum stress state after creep 2 years. 


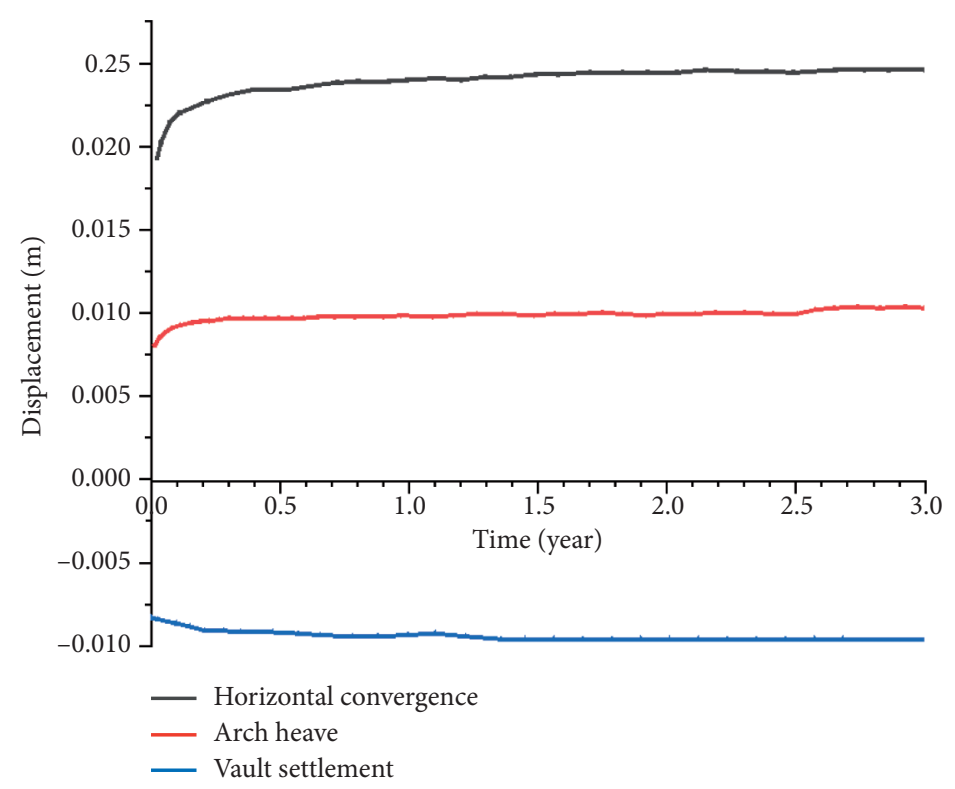

Figure 9: Tunnel second lining displacement-time curve.

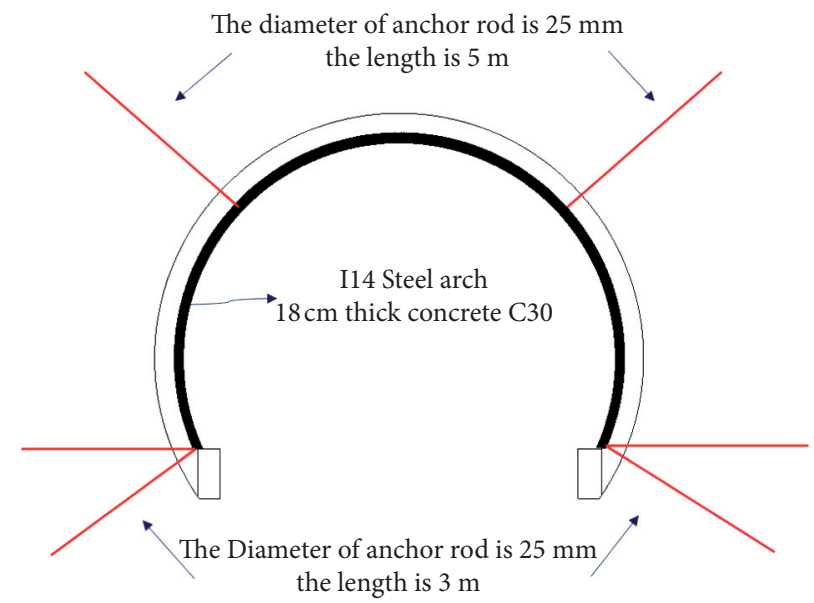

FIgURE 10: Reinforcement strategy of tunnel secondary lining.

\section{Conclusion}

In this paper, the interaction between tunnel secondary lining and surrounding rock creep is studied by using the numerical simulation method and combined with the characteristics of geological engineering. Taking Erlangshan Tunnel as a typical project, its in situ stress characteristics are analyzed, and the surrounding rock creep test is carried out.

Combined with the DFN numerical simulation method, the discrete element calculation model of failure mechanism of tunnel secondary lining structure after surrounding rock creep for 3 years is established, and the corresponding support design scheme is put forward. The study shows that the maximum principal stress in this area is horizontal and positively correlated with depth. The creep stress threshold of mudstone is low, and stress and time have a great influence on the creep characteristics of mudstone. After one year of construction, the second lining of the tunnel is stable.
The cracked section is reinforced by steel frame erection arch + anchor bolt; especially, the anchor bolt is added in the key failure area, which can effectively control the damage of tunnel secondary lining.

\section{Data Availability}

The data used to support the findings of the study are available within the article.

\section{Disclosure}

The authors would like to declare on behalf of the co-authors that the work described is original and has not been previously published.

\section{Conflicts of Interest}

The authors declare that they have no conflicts of interest. 


\section{Authors' Contributions}

The manuscript is approved by all authors for publication.

\section{Acknowledgments}

This research was financially supported by the State Key Laboratory for GeoMechanics and Deep Underground Engineering Open Foundation (SKLGDUEK1918). The supports are gratefully acknowledged and appreciated.

\section{References}

[1] G. Xu, C. He, Q. Yang, and B. Wang, "Progressive failure process of secondary lining of a tunnel under creep effect of surrounding rock," Tunnelling and Underground Space Technology, vol. 90, pp. 76-98, 2019.

[2] Y. Liu, P. Zheng, and P. Wang, "Multi-factors influence of anchorage force on surrounding rock under coupling effect of creep rock mass and bolt/cable," Geomatics, Natural Hazards and Risk, vol. 12, no. 1, pp. 328-346, 2021.

[3] K. Hu, Q. Feng, and H. Li, "Study on creep characteristics and constitutive model for thalam rock mass with fracture in tunnel," Geotechnical \& Geological Engineering, vol. 36, no. 2, pp. 827-834, 2018.

[4] C. Qi and A. Fourie, "Numerical investigation of the stress distribution in backfilled stopes considering creep behaviour of rock mass," Rock Mechanics and Rock Engineering, vol. 52, no. 9, pp. 3353-3371, 2019.

[5] Q. Y. Fan, J. Y. Lu, and Z. Zhu, "Experimental study on creep of surrounding rock mass in argillaceous soft rock tunnel," Applied Mechanics and Materials, vol. 194, pp. 826-830, 2012.

[6] W. Liu and S. Zhang, "An improved unsteady creep model based on the time dependent mechanical parameters," Mechanics of Advanced Materials and Structures, vol. 73, pp. 1-11, 2020.

[7] M. He, Q. Wang, and Q. Wu, "Innovation and future of mining rock mechanics," Journal of Rock Mechanics and Geotechnical Engineering, vol. 13, no. 1, pp. 1-21, 2021.

[8] C. Zhu, M.-C. He, M. Karakus, X.-H. Zhang, and Z. Guo, "The collision experiment between rolling stones of different shapes and protective cushion in open-pit mines," Journal of Mountain Science, vol. 18, no. 5, pp. 1391-1403, 2021.

[9] W. Liu and S. Zhang, "Creep parameter determination and model establishment considering stress and time effects," Geotechnical \& Geological Engineering, vol. 38, no. 2, pp. 1509-1520, 2020.

[10] H. Lin, X. Zhang, Y. Wang et al., "Improved nonlinear Nishihara shear creep model with variable parameters for rock-like materials," Advances in Civil Engineering, vol. 2020, pp. 1-15, 2020.

[11] Q. Wang, Z. Jiang, B. Jiang, H. Gao, Y. Huang, and P. Zhang, "Research on an automatic roadway formation method in deep mining areas by roof cutting with high-strength boltgrouting," International Journal of Rock Mechanics and Mining Sciences, vol. 128, Article ID 104264, 2020.

[12] Y. Wang, W. K. Feng, R. L. Hu, and C. H. Li, "Fracture evolution and energy characteristics during marble failure under triaxial fatigue cyclic and confining pressure unloading (FC-CPU) conditions," Rock Mechanics and Rock Engineering, vol. 54, no. 2, pp. 799-818, 2021.

[13] W. Huang, K. Wen, D. Li et al., "Experiment study of lateral unloading stress path and excess pore water pressure on creep behavior of soft soil," Advances in Civil Engineering, vol. 2019, pp. 1-9, 2019.
[14] X. Liu, X. Yang, and J. Wang, "A nonlinear creep model of rock salt and its numerical implement in FLAC3D," Advances in Materials Science and Engineering, vol. 2015, pp. 1-8, 2015.

[15] S. Huang, X. Meng, and G. Zhao, "Creep mechanics of the high-stress soft rock under grade unloading," Advances in Civil Engineering, vol. 2020, pp. 1-12, 2020.

[16] Q. Wang, Y. Wang, M. He et al., "Experimental research and application of automatically formed roadway without advance tunneling," Tunnelling and Underground Space Technology, vol. 114, no. 3, Article ID 103999, 2021.

[17] B. Li, R. Bao, Y. Wang, R. Liu, and C. Zhao, "Permeability evolution of two-dimensional fracture networks during shear under constant normal stiffness boundary conditions," Rock Mechanics and Rock Engineering, vol. 54, no. 3, pp. 1-20, 2021.

[18] F. Wu, R. Gao, J. Liu, and C. Li, "New fractional variable-order creep model with short memory," Applied Mathematics and Computation, vol. 380, Article ID 125278, 2020.

[19] F. Wu, H. Zhang, Q. Zou, C. Li, J. Chen, and R. Gao, "Viscoelastic-plastic damage creep model for salt rock based on fractional derivative theory," Mechanics of Materials, vol. 150, Article ID 103600, 2020.

[20] G. Li, Y. Hu, Q. B. Li, T. Yin, J. X. Miao, and M. Yao, "Inversion method of in-situ stress and rock damage characteristics in dam site using neural network and numerical simulation-a case study," IEEE Access, vol. 8, pp. 46701-46712, 2020.

[21] X. Li, X. Zhou, and Z. Xu, "Inversion method of initial in situ stress field based on BP neural network and applying loads to unit body," Advances in Civil Engineering, vol. 2020, pp. 1-15, 2020.

[22] J. Wang, J. Sun, and H. Kou, "Multiparameter inversion early warning system of tunnel stress-seepage coupling based on IA-BP algorithm," Advances in Civil Engineering, vol. 2021, pp. 1-19, 2021.

[23] Z. Liu, W. Ma, and S. Tian, "Study on the mechanical behavior of double primary support of soft rock tunnel under high ground stresses and large deformation," Advances in Civil Engineering, vol. 2020, no. 8, pp. 1-9, 2020.

[24] G. Li, W. Ma, S. Tian, Z. Hongbo, F. Huabin, and W. Zou, "Groundwater inrush control and parameters optimization of curtain grouting reinforcement for the Jingzhai tunnel," Geofluids, vol. 2021, no. 7, pp. 1-10, 2021.

[25] H. Mansouri and R. Ajalloeian, "Mechanical behavior of salt rock under uniaxial compression and creep tests," International Journal of Rock Mechanics and Mining Sciences, vol. 110, pp. 19-27, 2018.

[26] K. Hashiba and K. Fukui, "Time-dependent behaviors of granite: loading-rate dependence, creep, and relaxation," Rock Mechanics and Rock Engineering, vol. 49, no. 7, pp. 25692580, 2016.

[27] S. Nadimi, K. Shahriar, M. Sharifzadeh, and P. Moarefvand, "Triaxial creep tests and back analysis of time-dependent behavior of Siah Bisheh cavern by 3-dimensional distinct element method," Tunnelling and Underground Space Technology, vol. 26, no. 1, pp. 155-162, 2011.

[28] X.-J. Hao, X.-T. Feng, C.-X. Yang, Q. Jiang, and S.-J. Li, "Analysis of EDZ development of columnar jointed rock mass in the baihetan diversion tunnel," Rock Mechanics and Rock Engineering, vol. 49, no. 4, pp. 1289-1312, 2016.

[29] T. Kawamoto, Y. Ichikawa, and T. Kyoya, "Deformation and fracturing behaviour of discontinuous rock mass and damage mechanics theory," International Journal for Numerical and Analytical Methods in Geomechanics, vol. 12, no. 1, pp. 1-30, 1988. 